\title{
A Study of the Effects and Policy Implications of Flat Rate Tuition
}

Claudine Keenan, Gurprit Chhatwal, Jinchang Wang

Dean of Education The Richard Stockton College of New Jersey 101 Vera King Farris Drive

Associate Professor of Business Studies The Richard Stockton College of New Jersey 101 Vera King Farris

Drive.

Professor of Business Studies The Richard Stockton College of New Jersey 101 Vera King Farris Drive

\section{ABSTRACT}

At a four-year public college. This study shows that students are responsive to flat rate In the current era of decreasing public funding and increasing pressure to improve student performance, many schools are considering or have implemented flat rate tuition plans that allow students to take a higher course load for a fixed "flat" tuition. This study investigates the effects of flat rate tuition over the past eight years on course loads attempted by students, rate of withdrawal from classes and four-year graduation rates tuition, and flat rate tuition has had an over all positive effect on students' academic progress.

\section{Council for Innovative Research}

Peer Review Research Publishing System

Journal: INTERNATIONAL JOURNAL OF RESEARCH IN EDUCATION METHODOLOGY

Vol . 6, No.2

ijremeditor@gmail.com

www.ijrem.com 


\section{Introduction}

Public colleges at present are experiencing increased pressure to improve student degree completion rates and to keep tuition fees as low as practicable. Public and private 4-year colleges and universities report that graduation rates are between 23.5\% and 64\% (De Angelo etal., 2011). By linking completion rates to student indebtedness, the federal government has increased the pressure on colleges to improve on both of these measures (US Department of Education, 2011). At the same time, although private colleges and universities have depended on tuition and endowments as their main source of operating revenue for decades, their public counterparts have only recently seen such dramatic cuts in state funding that their own increasing dependence on tuition revenues has resulted in significant tuition increases for the group of students who generally cannot afford to attend private colleges (Delta Project, 2012).

In response to the pressures from federal government and the economic recession, public schools have been considering flat rate tuition, which allows students to take credisranging from twelve all the wayto eighteen or twenty, at the same tuition rate. By contrast, per-credit tuition requires students to pay for the actual number of credits they attempt each semester. Some colleges charge flat rate tuition for full-time students and per-credit tuition for part-time students. Full time status is generally defined as twelve or more creditsunder federal guidelines for a typical fifteen-week academic term. In this study, credits are synonymous with credits.

Flat rate tuition policieswere initiallydesigned to motivate and incentivize students to graduate on time (Sellingo, 2001; Waldman, 2004). An undergraduate degree usually requires completing 120-128 credits. A student who attempts twelve credits per semester for four years will complete just 96 credits or $80 \%$ of the credits required to completea degree. Thus, in the face of low graduation rates and high student debt, many public colleges have considered implementing flat rate tuition policies to encourage students to earn at least fifteen-sixteen credits per semester so that they may graduate within four years. However, students who attempt exactly $100 \%$ of the required classes during the four years must also succeed in passing every class attempted.This limits their flexibility in exploring or changing majors, and in adding a minor or another major. By contrast, students who attempt eighteen to twenty credits per semester may either graduate early, or have the flexibility during their four years in college to earn a double major, to change majors, or to earn a minoras well. Therefore, some public institutions have turned to flat rate tuitionfor its potential to attain the two goals: timely completion of degree and lower total tuition indebtedness.

Most institutions that have implemented flat rate tuition tend to set the "full time" threshold at the exact $100 \%$ line by which a student making satisfactory progress would graduate in four years, generally 15-16 credits per term. However, there is no agreement on that threshold between states (or even between institutions within the same state).

Although many colleges have implemented flat rate tuition policies, there have beenfew published studiesthat systematically investigate the effects of flat rate tuition on students and on the institutions. Our study useseight years'student data at RS College, a public four year college, which introduced flat rate tuition in fall 2009. It investigates the changes in students'courseload, class withdrawal rates, and students who complete the graduation requirements within four years before and after flat rate tuition. This study seeks to answer the following questions:

(1) How responsive are the students to flat rate tuition policy?

(2) What effect does flat rate tuition have on student overloads?

(3) What effect does flat rate tuition have on class-withdrawal rates in terms of headcount and seat-count?

(4) What effect does flat rate tuitionhave on the time students take to complete their undergraduate degree?

\section{Literature Review}

The study of different types of tuition policies by Yanikoski and Wilson (1984) focused on examining the rationale for adjusting tuition to achieve maximum tuition revenue in minimally regressive ways. The authors explained that the rationale for most institutions to charge higher tuition for graduate work compared to undergraduate programs was largely unquestioned for centuries: graduate students stood to earn more upon completing their degrees, their class sizes were generally smaller and their programs often required specialized, more expensive faculty, facilities, and more expensive equipment. They extended this last rationale in a discussion about applying similarly differentiated tuition prices among various undergraduate majors.

A small number of articles discussed adjusted differences between in-state vs. out-of-state tuition rates. Morgan concluded that out-of-state tuition was a deterrent to interstate migration (Morgan, 1983). Dougherty et al examined tuition rates as a battleground for states and undocumented residents (Dougherty, Nienhusser and Vega, 2010) and Flores found non-citizens 1.54 times more likely to enroll in colleges whose states initiated in-state tuition policies (2010).

As noted in the introduction, recent attention to college tuition has increaseddue to the decline of state support, forcing many formerly affordable colleges to pass on increasingly higher shares of their costs directly to students via higher tuition and fees. In the study of the impact of the "tax revolt" from the late 1970s and early 1980s, Archibald and Feldman (2006) found that state policies set in response to this political movement had remained in a constant mode of decreasing public support ever since, although institutions vary widely in how they responded with changes in their tuition policies. In a scholarly review of tuition policies for his study of linear tuition modeling, Troutt (1983) found that few institutions, let alone states, used consistent approaches to setting tuition, much less to raising it. The Troutt study looked closely at an actual case where the model was applied, and the Board at that institution opted to charge a per-credit increase that was very 
close to the amount that the linear model yielded. Heller expanded research on student demand theory over nearly twenty years of public college enrollment data by race, tuition and financial aid policies among all fifty states, culminating in a series of recommendations aimed at increasing equality of access (1999).

Additionally, Cheslock and Hughes (2011) found that the population shift away from the high-tuition northeastern region towards the low-tuition southern region of the US also had an impact on the loss of public support and resulting increases in tuition in those regions. Moreover, the relationship between enrollment behavior and general tuition increases was the focus of some studies reviewed by Curs and Singell (2010). Like many researchers whose work preceded theirs, they found that student enrollment rates were surprisingly unresponsive to changes in tuition. Their model demonstrated less responsiveness among high ability, low need students than their low ability, high need counterparts. Shin and Milton (2006) acknowledged conflicting results on student sensitivity to tuition increases. They argued that economic cycles and external forces accounted for these conflicts in students' sensitivity to tuition increases.

Chhatwal et al.(2013) looked at the relationship between a newly-implemented flat rate tuition policy and undergraduate student performance (changes in GPA) and persistence (credits attempted vs. earned) at a public college during four consecutive academic terms. The study revealed a strong correlation between student persistence and performance. Students who attempted lower course loads were more likely to persist than those who attempted heavier course loads. These correlations were statistically significant so that they might be extrapolated to the whole student population at that college.

There have been no additional studies thatinvestigate the effects of flat rate tuition in particular; such as the effect of flat rate tuition on students' overload activity, the impact of flat rate tuition on class withdrawal ratesand on how long it takes students to graduate. This study focuses on these effects of flat rate tuition implemented five years agoat RSC.

\section{Materials and Methods of the Study}

RS College was founded in 1969 and opened its doors to approximately 1,000 students in 1971. Since then the College has grown to enroll more than 8,400 students, approximately 900 of whom are graduate students. Over its 45 year history, the College has grown from a handful of academic "divisions" to seven academic schools: Arts and Humanities; Business Studies; Education; General Studies; Health Sciences; Natural Sciences and Mathematics; and Social and Behavioral Sciences.

RSC switched from per-credit tuition to flat rate tuition for undergraduates in fall 2009. The flat rate tuition is set at what would be charged for 16 credits if flat rate did not exist. It remains "flat" for students taking between 12 and 20 credits per semester. That is, students who take 12 to 20 credits are charged the flat rate. Therefore, students who attempt 17 or more credits stand to benefit from the flat rate tuition policy. Students who take 11or fewer creditsare charged on a percredit basis.

This study looks at full time undergraduate students at RSC during the period fall 2006(three years per-credit rate) through spring 2013 (five years flat rate). Summer records were excluded from our data because RSC offers per-credit tuition only during summer terms. To control for the effect of progress made outside our own institution, students receiving any transfer credits from another institution during a "stop out" semester were not included in our data. Students in the graduate program and part-time undergraduate students were not included as the flat rate tuition policy does not apply to them. More than thirty thousand records were collected, compiled and analyzedin this study. For this type of study, formal consent is not required.

\section{Results: Effects of Flat Rate Tuition}

The analyses of student data for the past eight years are presented in this section. We will show the effects of flat rate tuition on students' course load, class withdrawal rate, and four-year graduation rate. Of the eight years in our study, 2006-2008 were under the traditional per-credit tuition policy, and 2009-2013 were under the flat rate tuition policy.

We use the termflat rate beneficiary $(F R B)$ torefer to a student who takes 17 or more credits in a semester, so that $s / h e$ could benefit financially from the flat rate tuition policy., A non-flat rate beneficiary (NonFRB) refers to a student who takes 12 to 16 credits, so that $s$ he is a full time student, but didnotstand to benefitfinancially from this policy. For the convenience of comparing what happened prior to and after the implementation of flat rate tuition, students who took 17 or more credits in a semester before the implementation of flat rate tuitionare also called FRBs in our discussion; and students who took 12 to 16 credits in a semester before flat rate tuition are also called NonFRBs. A full-time studenttakes 12 or more credits, irrespective of beingFRBor NonFRB.

\subsection{Effects on Students' Course Load}

One intention of flat rate tuition is to encourage capable students to take more classes per semester to speed up the completion of their degree programs. In this section, we present the results of our analysis on how many students responded to flat rate tuition by taking a higher course load, and how many credits they attempted and dropped. We address these issues in terms of student headcount and class seat count.

\subsubsection{Total FRB Credits}

Table 1 and Figure 1 show the year-by-year total numbers of FRBcredits from 2006 to 2013. Total FRB credits are defined as the total number of creditstaken byFRB students in a semester. In 2006, 2007, and 2008, when per-credit tuition policy was in use, total FRB creditsremained at a relatively constant level around 20,000 credits. In fall 2009 upon the 
implementation of flat rate, there was a sharp increase to almost 30,000 credits. It then continued to increase steadily and reached to near 46,000 credits in 2013 , which is a $130 \%$ increase. The sharp increase of total FRB credits, which is much higher than the $20 \%$ increase of the institutional enrollment during those years, shows that students were very responsive to the newly implemented flat rate tuition policy.

Table 1. Total FRB credits

\begin{tabular}{cccccccc}
\hline F06 & F07 & F08 & F09 & F10 & F11 & F12 & F13 \\
\hline 19,898 & 19,720 & 20,300 & 29,726 & 32,948 & 36,806 & 42,222 & 45,940 \\
\hline
\end{tabular}

Figure 1. Total FRBCredits

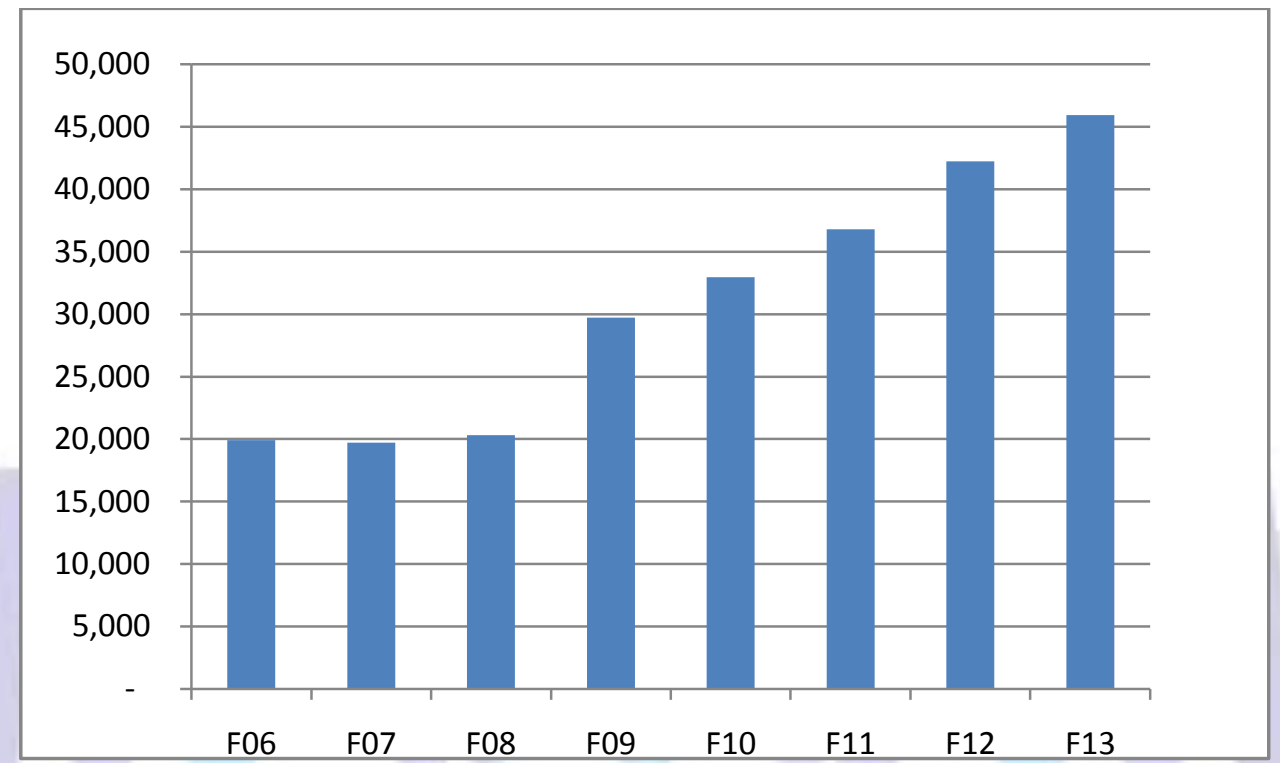

\subsubsection{Headcount of FRB and NonFRB}

Table 2 and Figure 2 compare FRB with Non FRB in terms of headcount. NonFRB shave always out numbered FRBs. However, in the five years since implementing flat rate, the size of this gap has been quickly decreasing. Before fall 2009 , the ratio between NonFRBs and FRBs was about 4.6 to 1 (4,780/1,073 in fall 2008). This ratio reduced to 1.9 to 1 in 2013 $(4,535 / 2,382)$. More NonFRBs began to take advantage of FRBflat rate benefits during those five years.

In the six year period from2008, one year before flat rate tuition,to 2013 , the number of FRB students increased by $122 \%$ from 1,073 to 2,382 , compared to an $18 \%$ increase infull time students from 5,853 to 6,917 and a $5 \%$ decrease of NonFRBs from 4,780 to 4,535 . The trend of the increase of FRBsappearsto be continuing steadily, signaling that students are opting to benefit from flat rate in greater numbers.

Table 2. Headcounts over Years

\begin{tabular}{lllllllll}
\hline & F06 & F07 & F08 & F09 & F10 & F11 & F12 & F13 \\
\cline { 2 - 8 } FRBs & 1,050 & 1,040 & 1,073 & 1,556 & 1,716 & 1,913 & 2,188 & 2,382 \\
NonFRBs & 4,685 & 4,809 & 4,780 & 4,488 & 4,544 & 4,619 & 4,584 & 4,535 \\
Total & 5,735 & 5,849 & 5,853 & 6,044 & 6,260 & 6,532 & 6,772 & 6,917 \\
\hline
\end{tabular}


Figure 2. Headcounts of FRBs and NonFRBs

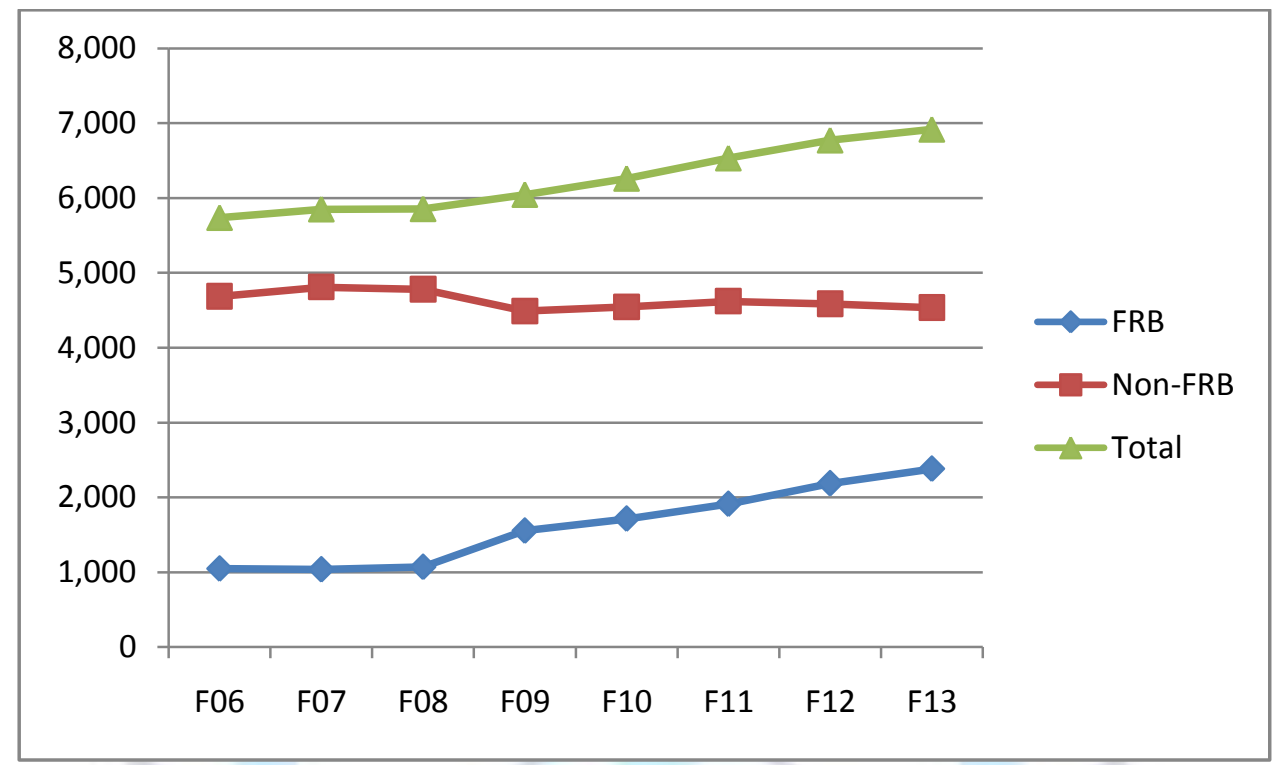

\subsubsection{Percentages of FRB and Non FRB}

Table 3 and Figure 3 show year-by-year percentages of FRBs and percentages of Non FRBs in all full time students. The percentage of FRBs in all students started increasing from 2009 when flat rate tuition was implemented. It was nearly doubled from about $18 \%$ in 2006 through 2008 to $34.4 \%$ in 2013 . That is, by 2013 , one in three full time students was a FRB

Table 3. Percentage of FRBs and NonFRBs in all full-time students

\begin{tabular}{lllllllll}
\hline & F06 & F07 & F08 & F09 & F10 & F11 & F12 & F13 \\
\cline { 2 - 8 } FRB $\%$ & $18.3 \%$ & $17.8 \%$ & $18.3 \%$ & $25.7 \%$ & $27.4 \%$ & $29.3 \%$ & $32.3 \%$ & $34.4 \%$ \\
NonFRB & $81.7 \%$ & $82.2 \%$ & $81.7 \%$ & $74.3 \%$ & $72.6 \%$ & $70.7 \%$ & $67.7 \%$ & $65.6 \%$ \\
\hline
\end{tabular}

Figure 3. \% of FRBs in All Full-time Students

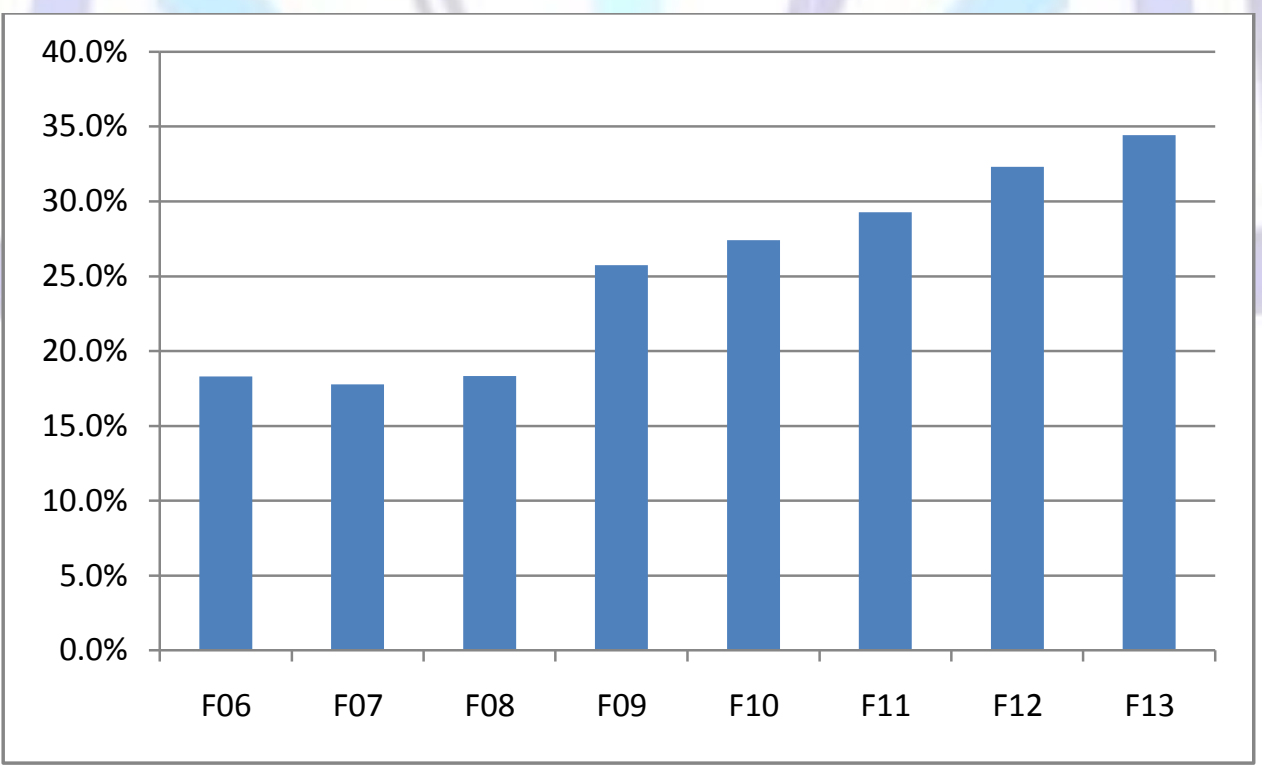




\subsubsection{Seat count of FRB and Non FRB}

Table 4 and Figure 4 compare FRB students with Non FRB students in terms of seat count. "Seat count" refers to the class seats taken by students. If a student enrolls into a class, then the seat count goes up by one. If a class has 35 students enrolled, then the class has a 35 seat count. If a student drops a class, then total seat count is reduced by one to 34.

Total seats taken by FRBs steadily increased after the implementation of flat rate tuition in 2009. Itwent up to 12,813 seats in 2013 from 5,695 in fall 2008. AlthoughNonFRBs stilltook more seats, FRBs closed thatgap significantly.

\section{Table 4. Seat Count over Years}

\begin{tabular}{lllllllll}
\hline & F06 & F07 & F08 & F09 & F10 & F11 & F12 & F13 \\
\hline By FRBs & 5,582 & 5,567 & 5,695 & 8,212 & 9,046 & 10,131 & 11,596 & 12,813 \\
By NonFRBs & 17,956 & 18,400 & 18,425 & 17,373 & 17,656 & 18,131 & 18,010 & 18,197 \\
Total seats taken & 23,538 & 23,967 & 24,120 & 25,585 & 26,702 & 28,262 & 29,606 & 31,010 \\
\hline
\end{tabular}

Figure 4. Seats taken by FRBs and nonFRBs

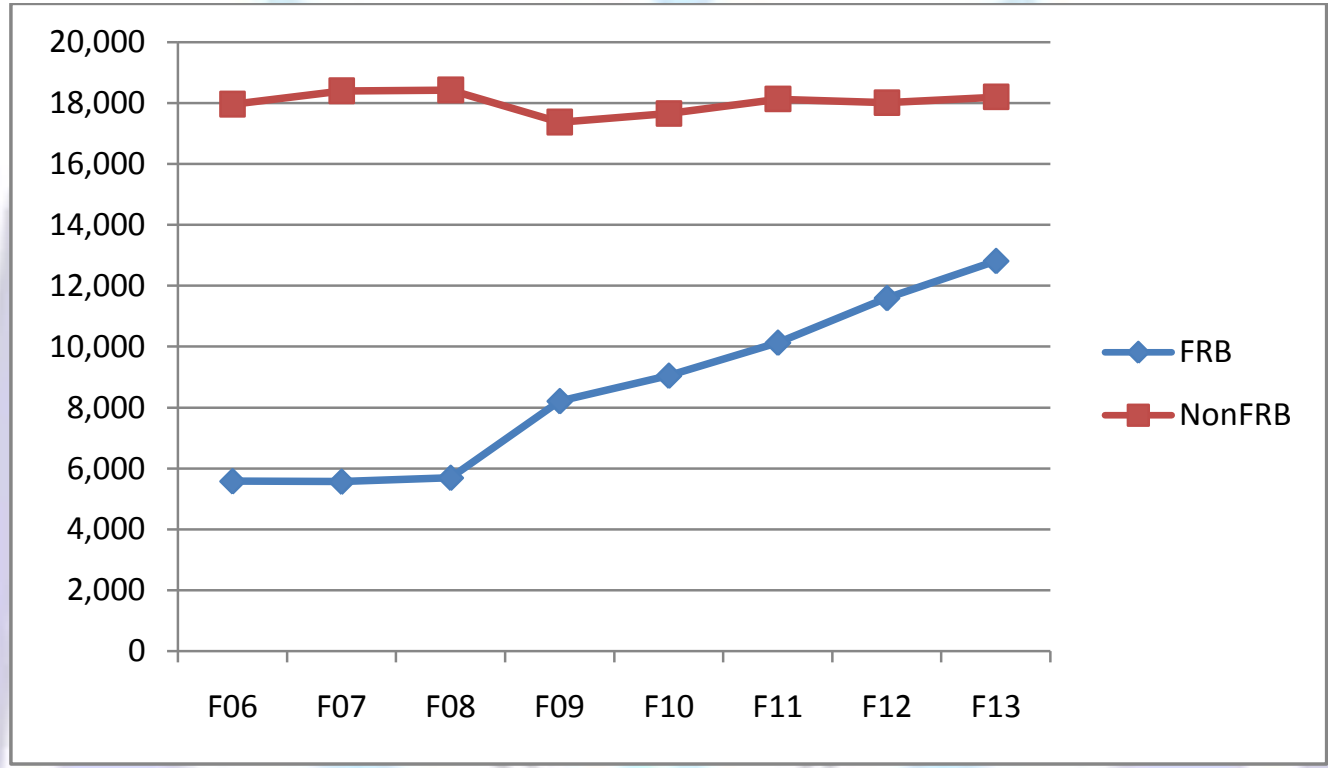

\subsubsection{Percentage of class seats taken by FRBs and NonFRBs}

Table 5 and Figure 5 compare the percentages of class seats taken by FRBs and NonFRBs. After 2009 when flat rate tuition started, the percentage of FRBs in a class kept increasing, while the percentage of NonFRBs kept decreasing.Prior to 2009 , on average only one in four students in a class (23\%) was a FRB. In 2013 , two in five students in a class (41.3\%) were FRBs.

Table 5. Percentages of Class Seats Taken FRBs and NonFRBs

\begin{tabular}{lllllllll}
\hline & F06 & F07 & F08 & F09 & F10 & F11 & F12 & F13 \\
\hline \% by FRBs & $23.7 \%$ & $23.2 \%$ & $23.6 \%$ & $32.1 \%$ & $33.9 \%$ & $35.8 \%$ & $39.2 \%$ & $41.3 \%$ \\
$\%$ by NonFRBs & $76.3 \%$ & $76.8 \%$ & $76.4 \%$ & $67.9 \%$ & $66.1 \%$ & $64.2 \%$ & $60.8 \%$ & $58.7 \%$ \\
\hline
\end{tabular}


Figure 5. Percentage of FRBs and NonFRBs in a Class

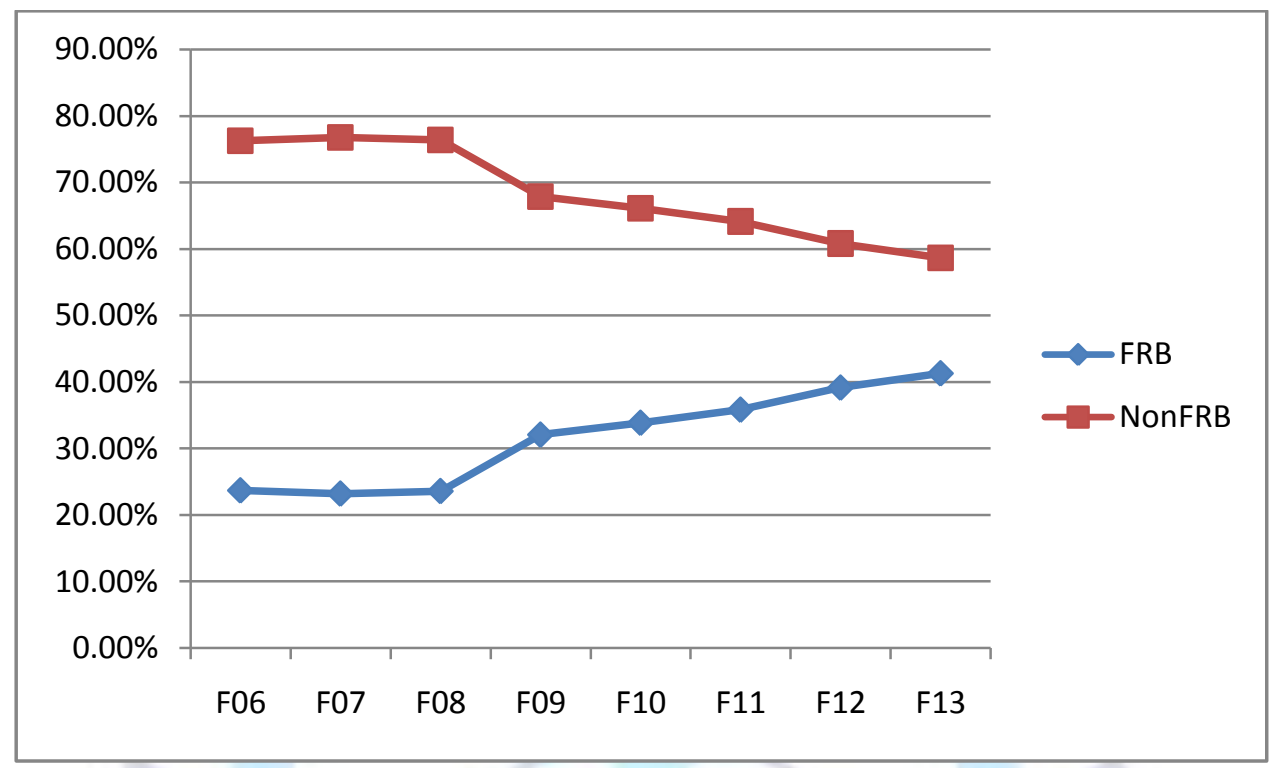

\subsection{Effects on Class Withdrawal Rate}

Amajor reason students are believed to withdraw from a class is theirinability to handle the course load attempted. We presumed the overall withdrawal ratewould increase after implementingflat rate tuition, because students mightattempt more than they are able to handle. Our data, however,does not confirm thispresumption.

\subsubsection{Withdrawal Rate of FRBs and NonFRBs}

Table 6compares class withdrawals among three groups of students:FRB students, Non-FRB students, and all full-time students. A student was counted as a "class withdrawal student" if s/he dropped at least one class.

The withdrawal rate for a group Xis equal to:

\section{Number of students who were in group $X$ and dropped one or more classe(s)}

\section{Total number of students in group $X$}

For example, the first row in Table 6 is forX=FRB, so thewithdrawal ratefor this group is equal to [number of FRBs who dropped one classor more] divided by [total number of FRBs]. For the group of all full time students, as shown in the last row in Table 6, $\mathrm{X}=$ All full-time students, so the withdrawal rate for this group is equal to [number of full time students who dropped one classor more] divided by [total number of full-time students]. Figure 6 displays graphically the changes of the withdrawal rates for FRB group and NonFRB group over years.

\section{The summarized data in Table 6 and Figure 6 reveal the following facts:}

(a) Class withdrawal rate for FRBs has always been higher than the other two groups, NonFRBs and all full-time students, regardless of flat rate tuition policy.

(b) Class withdrawal rate forFRBs rose sharply from twenty percent in 2008 to twenty six percent in 2009 when flat rate tuition was first introduced. It shows that more students enrolled in one or two additionalclasss,attempting to take advantage of the new policy. However, some of themmay not have been prepared well enough for the additional overload, and ended up dropping some classes.

(c) After the initial increase in 2009, FRBs' class withdrawal rate kept going down. Studentsmay have become better informed about flat rate tuition, adjusting theirbehavior accordingly.

(d) FRBs'withdrawal rate leveled off in 2012 and 2013toa level similar to thatin the pre-flat rate years2006 - 2008. Consequently, fall 2009 to 2012 may be viewed as the transition periodfor flat rate tuition. Now that this period is over, we expect that FRBs' class withdrawal rate will continue to level offeven further after fall 2013.

(e) The class withdrawal rates for all full-time students in 2012 and 2013 arelower than those in the threepre-flat rate years before 2009. Although we saw a temporary increase in the withdrawal rates among all full-time students during the initial implementation of flat rate,the long-term trend of withdrawal rate reflected in our data does not support theapriori expectation of a sustained higher class withdrawal rate associated with flat rate tuition. 
Table 6 Withdrawal Rate of $X$ students = (\# of $X$ students who dropped $\geq 1$ class) $/$ (\# of $X$ students)

\begin{tabular}{lllllllll}
\hline & $\mathrm{F} 06$ & $\mathrm{~F} 07$ & $\mathrm{~F} 08$ & $\mathrm{~F} 09$ & $\mathrm{~F} 10$ & $\mathrm{~F} 11$ & $\mathrm{~F} 12$ & $\mathrm{~F} 13$ \\
\cline { 2 - 8 } X=FRB & $21.2 \%$ & $17.5 \%$ & $20.8 \%$ & $26.3 \%$ & $25.2 \%$ & $23.6 \%$ & $19.6 \%$ & $18.7 \%$ \\
X=NonFRB & $15.6 \%$ & $14.5 \%$ & $16.8 \%$ & $16.5 \%$ & $16.4 \%$ & $15.9 \%$ & $13.1 \%$ & $12.8 \%$ \\
X=All students & $16.6 \%$ & $15.0 \%$ & $17.5 \%$ & $19.0 \%$ & $18.8 \%$ & $18.2 \%$ & $15.2 \%$ & $14.8 \%$ \\
\hline
\end{tabular}

Figure 6.Withdrawal rates of FRBs and NonFRBs

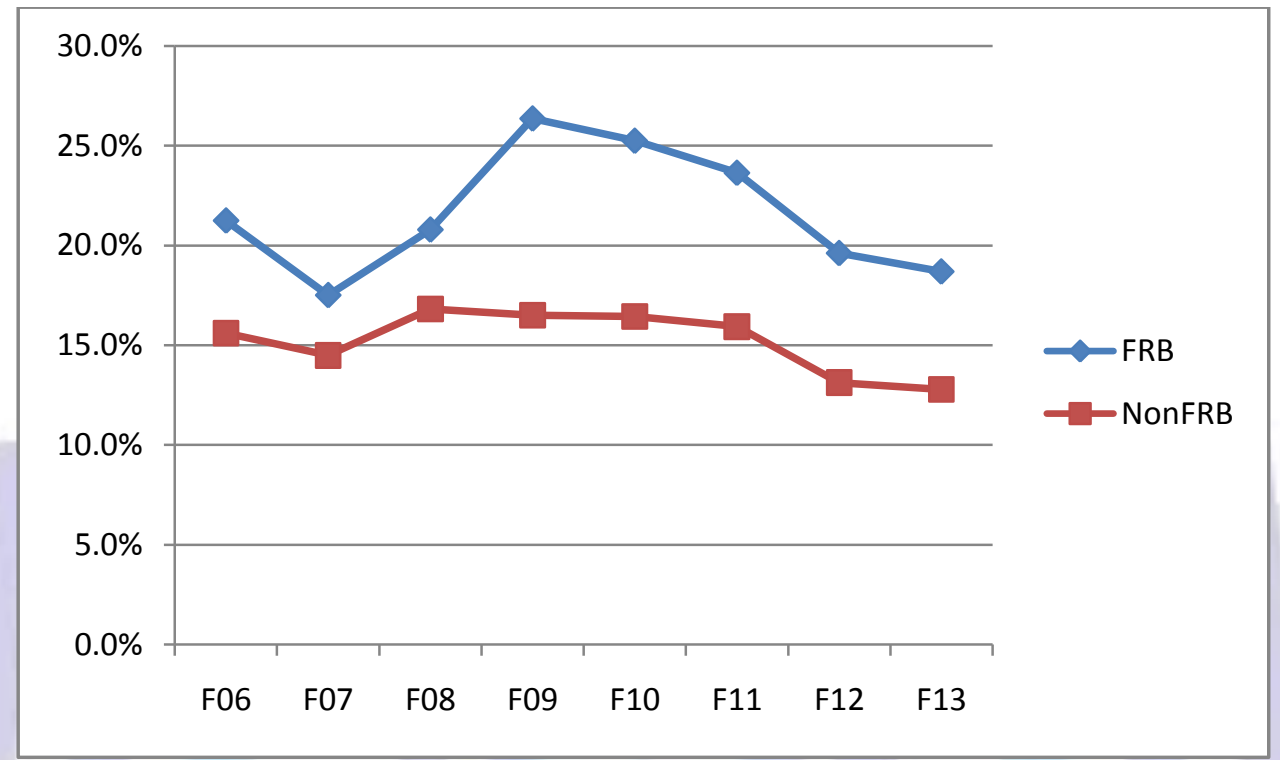

Upon observing the withdrawal rate among FRBs in 2009, the institution strengthened its Satisfactory Academic Progress (SAP) system for all students in 2010, which may have contributed to a decrease and subsequent stabilization of the withdrawal rate for both groups. The college's SAP requires every student to remain within a $25 \%$ withdrawal rate of all attempted course work, but the previous implementation resulted only in a mandatory advising session for students whose withdrawal rates exceeded that limit. However, in 2010, the institution restricted flat rate eligibility only to those students who achieved Satisfactory Academic Progress. As a result, Table and Figure 6 show that the withdrawal rates for both groups went down after this change was implemented.

\subsubsection{Proportion of FRBs in full time students who drop one classor more}

Table 7 compares the withdrawal rate of FRB and NonFRB each to the whole population.For example, the first row shows the proportion of FRBs who dropped at least one class, where the whole population of full-time students includes bothFRBs and NonFRBs. It is equal to:

$$
\frac{\text { (number of FRBs who dropped one class or more ) }}{\text { (number of full -time students who dropped one class or more) }} \text {. }
$$

Before implementing flat rate tuition policy, only a little more than $20 \%$ of full-time students who dropped a class or more were FRBs. After introducing flat rate tuition in 2009, that proportion significantly increased and eventually reached $43 \%$ in 2013. In the same time span, the proportion of NonFRBs decreased from $78 \%$ to $57 \%$. Figure 7 showsgraphically the year-by-year proportions of FRBs and NonFRBs.

Table 7. Proportion of X-students in all full-time students who dropped one class or more $=(\#$ of $X$ students who dropped one or more) / (total \# of students who dropped one or more)

\begin{tabular}{lllllllll}
\hline & F06 & F07 & F08 & F09 & F10 & F11 & F12 & F13 \\
\cline { 2 - 8 } X=FRB & $23.38 \%$ & $20.71 \%$ & $21.71 \%$ & $35.62 \%$ & $36.69 \%$ & $38.0 \%$ & $41.61 \%$ & $43.41 \%$ \\
X=NonFRB & $76.62 \%$ & $79.29 \%$ & $78.29 \%$ & $64.38 \%$ & $63.31 \%$ & $61.95 \%$ & $58.39 \%$ & $56.59 \%$ \\
\hline
\end{tabular}


Figure 7. Proportions of FRBs and NonFRBsin students who dropped some classes

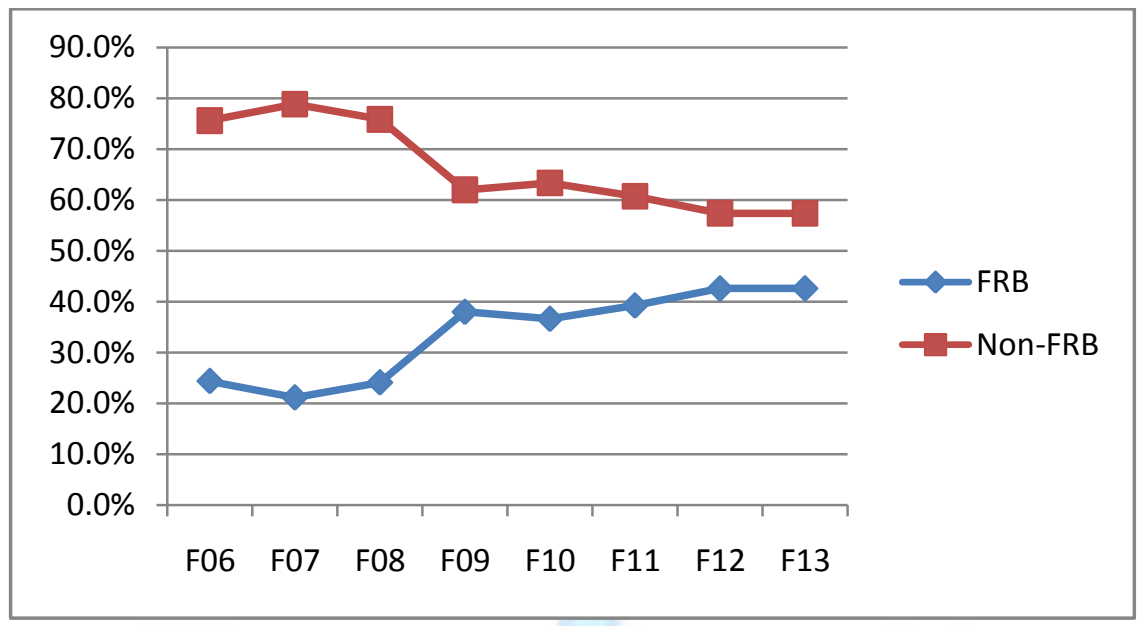

\subsubsection{Class seat drop rate of FRBs and NonFRBs}

Table 8 shows the class seat drop rates of FRBand NonFRB in terms of class seats. Class seat drop rate forFRB isthe percentage ofFRBswho withdraw from a class duringany semester. It is equal to:

(total number of class seats dropped by FRBs )

(total number of class seats taken by FRBs at the beginning of a semester).

Class seat drop rate of FRB is actually the frequency or probability that a FRBenrolled in a class ends up dropping the class.If class seat drop rate of FRB is $5 \%$, for example, then itmeans that a class seat taken at the beginning of a semester by a FRBhas a $5 \%$ chance of beinglost by the end of the semester, or in other words, if a class initially has 20 FRBsenrolled, then $1(20 * 5 \%)$ of the 20 students on average would withdraw before the end of the semester.

Class seat drop rate of NonFRB ispercentage of NonFRBswho drops a seat in a semester. It is equal to:

(total number of class seats dropped by NonFRBs )

(total number of class seats taken by NonFRBs at the beginning of a semester ).

Class seat drop rate of FRBs experienced a sharp increase in 2009 when flat rate was first implemented. It thenkept decreasing. Note that class seat drop rate of NonFRBs also had a downward trend. But the rate of FRBs decreasesfaster thanthat of NonFRBs. In fall 2013, FRB and NonFRBhad similar class seat drop rates. Moreover, the class drop rate of FRBs in 2013 is even lower than the class seat drop rates of NonFRBs in the years before flat rate, 2006, 2007, and 2008. The overall class seat drop rate after five years of flat rate was $1 \%$ lower than it was before flat rate.

Before flat rate tuition was implemented at RSC, some faculty were concerned that the move would cause a high class drop rate. Some speculated that a class with 35 students initially enrolled may end up with 25 or even 20 students by the end of the semester.It was also suggested that class sizes be raised to provide room for the expected higher withdrawal rate. Five years after implementation of flat rate tuition shows that this concern did not bear out, as flat rate tuition did not cause higher class withdrawal rates after the transition period.

Table 8.Class Seats Drop Rate of FRB and NonFRB

\begin{tabular}{ccccccccc}
\hline & $F 06$ & $F 07$ & $F 08$ & $F 09$ & $F 10$ & $F 11$ & $F 12$ & $F 13$ \\
\cline { 2 - 8 } FRB & $5.8 \%$ & $4.9 \%$ & $6.1 \%$ & $7.4 \%$ & $6.8 \%$ & $6.1 \%$ & $5.2 \%$ & $4.7 \%$ \\
NonFRB & $5.6 \%$ & $5.5 \%$ & $6.0 \%$ & $5.7 \%$ & $6.0 \%$ & $5.3 \%$ & $4.5 \%$ & $4.4 \%$ \\
\hline
\end{tabular}


Figure 8. Class Seat Drop Rate of FRB and NonFRB

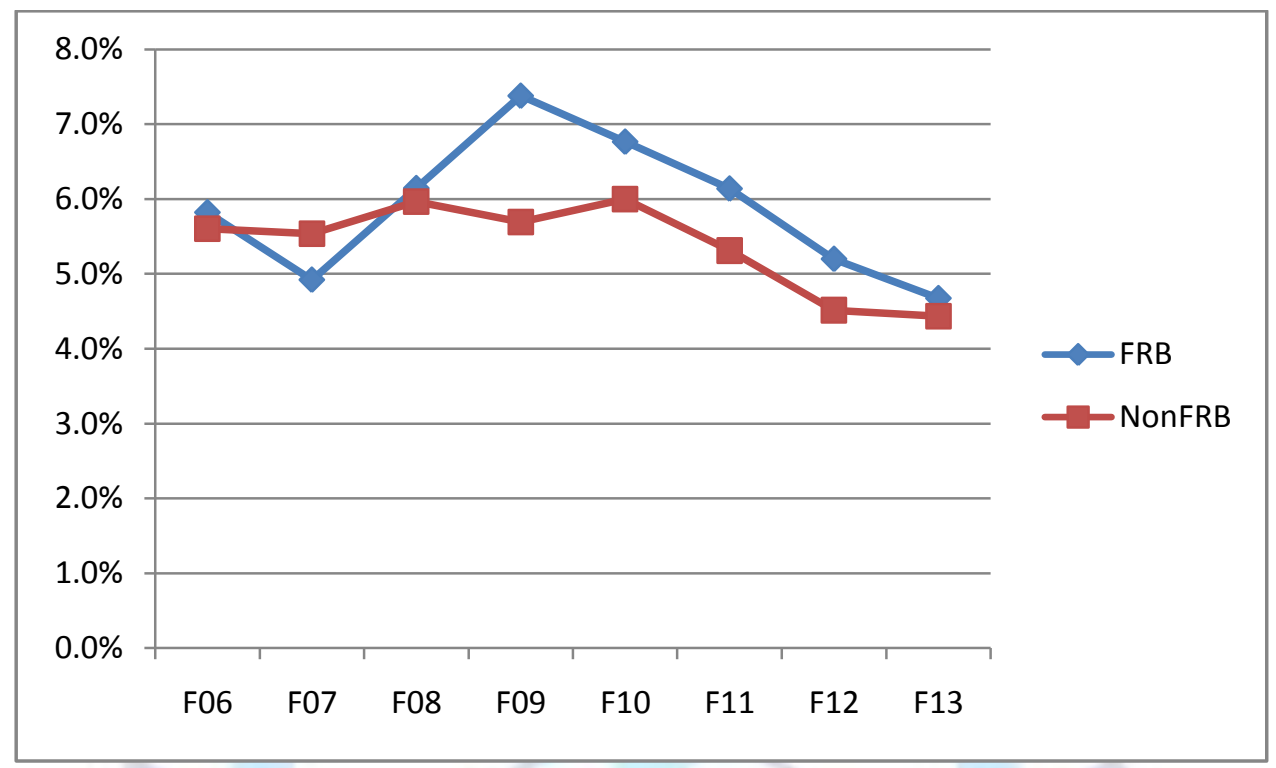

\subsubsection{Proportions of seats dropped by FRB and NonFRB}

Table 9 and Figure 9 show the proportions of seats dropped by FRBs and NonFRBs among all the seats dropped in a semester. The Proportion of seats dropped by FRBs is equal to:

number of seats dropped in a semester by FRBs

(number of seats dropped ina semester by fulltime students including both FRBs and NonFRBs) The Proportion of seats dropped by NonFRBsis equal to one minus the proportion of seats dropped by FRBs.

Of the class seats lost, most were due toNonFRB'swithdrawal in each of the eight years, since NonFRBs outnumbered FRBs as shown in 4.1.2. Butthe proportionof seats dropped by FRBs continued to increase after fall 2009 when flat rate tuition was first introduced, and reached $43 \%$ in 2013, i.e., for aseat withdrawn ,the chance that it was a FRB student was $43 \%$. Although class seat drop rate of FRBs kept decreasing to arrive at a level similar to that of NonFRB (see 4.2.3), proportion of seats dropped by FRB skept increasing. That is because of the rapid increase in the number of FRBs between 2009 and 2013 (see 4.1.1).

Table 9. Proportions of Class Seats Dropped by FRBs and NonFRBs

\begin{tabular}{ccccccccc}
\hline & F06 & F07 & F08 & F09 & F10 & F11 & F12 & F13 \\
\cline { 2 - 9 } FRBs & $24.4 \%$ & $21.2 \%$ & $24.2 \%$ & $38.0 \%$ & $36.6 \%$ & $39.2 \%$ & $42.6 \%$ & $43 \%$ \\
NonFRBs & $75.6 \%$ & $78.8 \%$ & $75.8 \%$ & $62.0 \%$ & $63.4 \%$ & $60.8 \%$ & $57.4 \%$ & $57.4 \%$ \\
Total seats dropped & 1,331 & 1,293 & 1,449 & 1,595 & 1,671 & 1,585 & 1,416 & 1,406 \\
\hline
\end{tabular}


Figure 9. Proportions of Class Seats Dropped byFRBs and NonFRBs

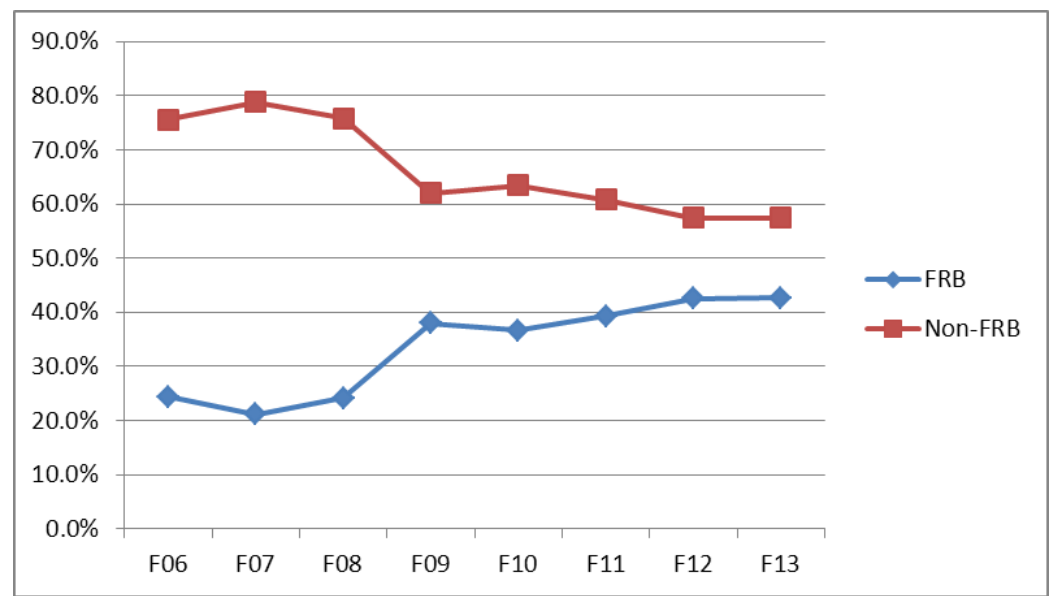

\subsection{FRB, GPA and Four-year Graduation Rate}

In this section, we look at GPA and four-year graduation rate before and after flat rate tuition.

\subsubsection{GPA of FRB and NonFRB}

A recentstudy showed that students with higher GPAs tended to take greater advantage of flat rate tuition (Chhatwal, Keenan,\&Wang, 2013). The eight-year data in this study confirmthat observation. Table 10 shows students cumulativeGPAs. Figure 10 graphically demonstrates thatFRBs consistently had higher GPAs than NonFRBs.

We do not think that the correlation between FRB and GPA indicates the effect of flat rate tuition. The correlation reveals a tendencyfor higher GPA students to take greater advantage of flat rate tuition.

Table 10. Average cumulative GPAs

\begin{tabular}{lllllllll}
\hline & F06 & F07 & F08 & F09 & F10 & F11 & F12 & F13 \\
\cline { 2 - 8 } FRB & 2.66 & 2.76 & 2.75 & 2.80 & 2.92 & 2.94 & 2.94 & 2.93 \\
NonFRB & 2.55 & 2.58 & 2.59 & 2.67 & 2.65 & 2.78 & 2.71 & 2.70 \\
\hline
\end{tabular}

Figure 10. Average Cumulative GPAs of FRB and NonFRB

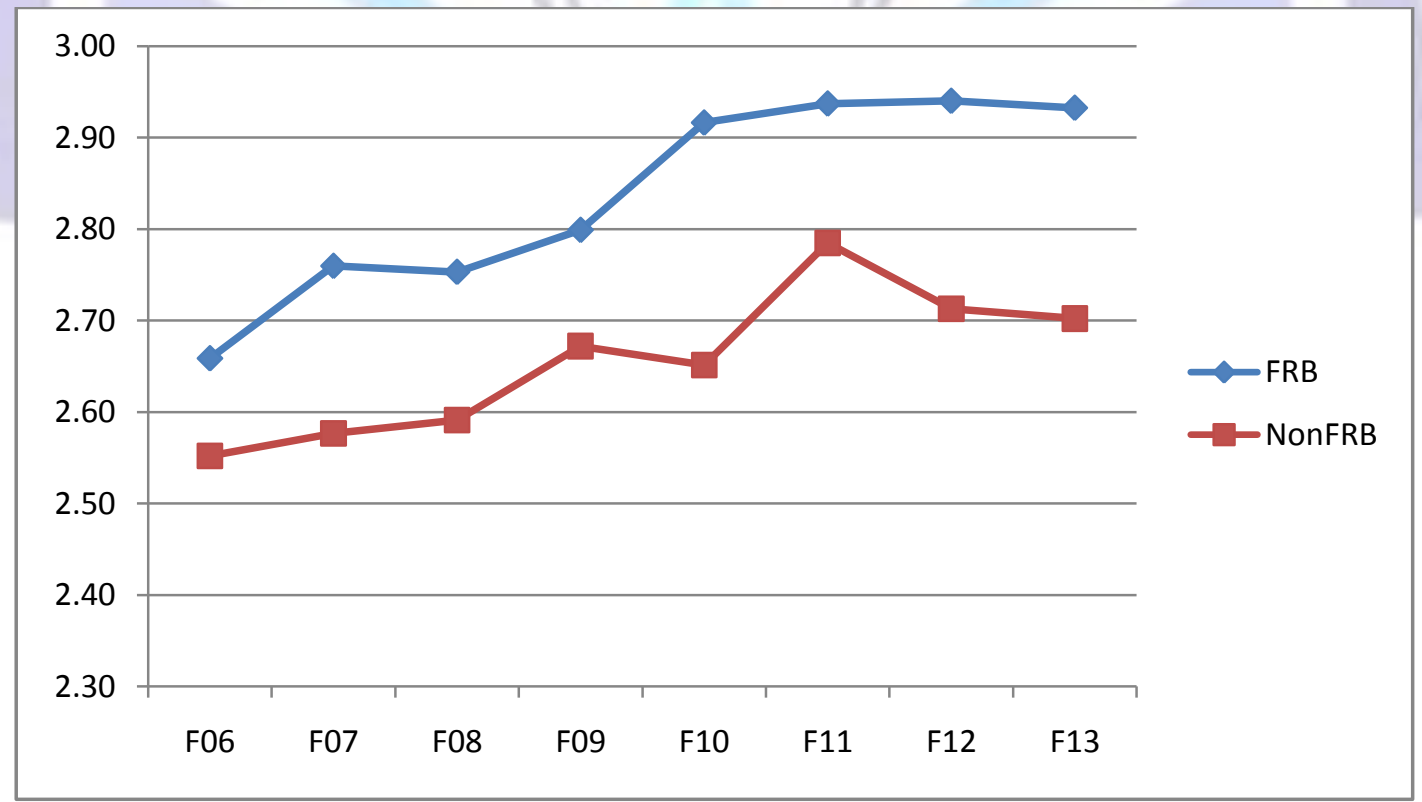




\subsubsection{Four-Year Graduation Rate}

As noted in the Introduction section, many institutions are considering flat rate tuition for its potential to speed the process for students to complete their degree requirements, which may also reduce student indebtedness. Table 11 shows fouryear graduation rates. Four-year graduation rateis defined as the percentage of first-time students who complete their degree requirements within four years at the same institution.

Table 11. Four-Year Graduation Rates for student cohort with entering year

\begin{tabular}{lcccccccc}
\hline $\begin{array}{l}\text { Year } \\
\text { entered }\end{array}$ & 2002 & 2003 & 2004 & 2005 & 2006 & 2007 & 2008 & 2009 \\
\hline Rate & $42 \%$ & $41.3 \%$ & $40.4 \%$ & $42.9 \%$ & $40.3 \%$ & $42.2 \%$ & $50.6 \%$ & $53.1 \%$
\end{tabular}

Figure 11. Four-Year Graduation Rates for student cohorts with entering year

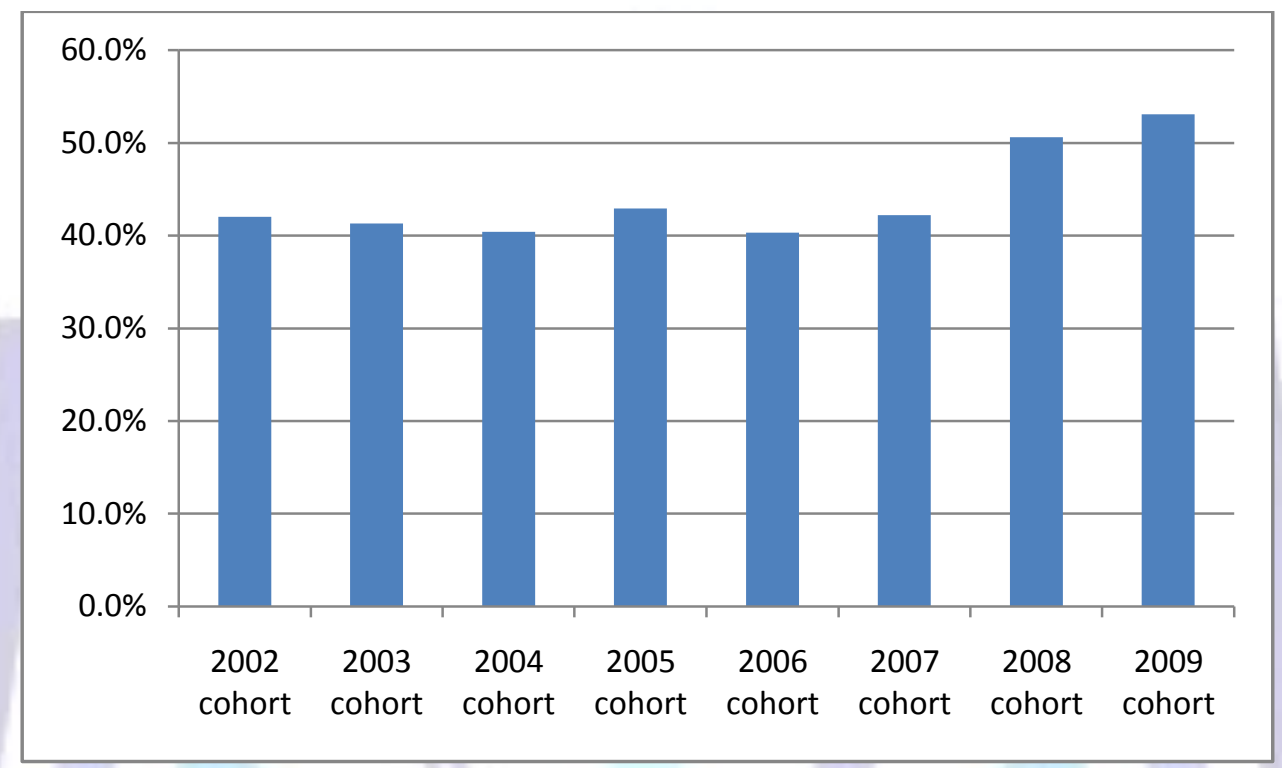

While the data are not disaggregated by FRB and NonFRB, the overall trend is apparent. The cohort of 2008 freshmen was able to avail themselves of the flat rate for three years of study. Theirfour-year graduation rate shows a sharp increase to $50.6 \%$. The four-year graduation rate for the cohort of 2009 freshmen, who had all four years of flat rate available, is even higher at $53.1 \%$. This finding indicates apreliminary positive effect of flat rate tuition and the timely completion of degrees.

\subsection{A Summary of the Effects}

Themajor effects of flat rate tuition illustrated by our study are as follows:

a) Afterimplementing flat rate tuition, total overload creditsat increased by almost $130 \%$ in five years (see 4.1 .1$)$. This findingillustrates that students were very responsive to flat rate in attempting higher course loads.

b) Prior to flat rate tuition, only about $18 \%$ of students took 17 or more credits per semester. After five years of flat rate tuition, $35 \%$ of students enrolled in 17 or more creditseach semester. These studentsoccupied about $40 \%$ of al class seats (see 4.1.2, 4.1.3 and 4.1.4). This finding shows a significant effect of flat rate tuition on students takingoverloads.

c) The class drop rate of FRB students kept going down during the five-year "transition" period, and came to about the same level as the rate of NonFRB, and to a level even lower than the overall drop rate before flat rate(see 4.2.3). Thisdisproves the a prioripresumption that flat rate tuition would cause higher class drop rates.

d) Although class withdrawal rate of FRB students has always been higher than NonFRB students, the gap between FRB and NonFRB students continues to narrow (see 4.2.4).

e) Students with higher GPAs tended to take greater advantage of flat rate tuition (see 4.3.1).

f) Flat rate tuition appears to have a preliminary positive effect onthe four-year graduation ratefor which it was designed and implemented (see 4.3.2). 


\section{Discussion and Implications for Further Study}

The eight-year data in this study shows that the implementation of flat rate tuition policy atRSC of New Jersey successfully encouraged capable students to take higher course loads. After an initial and significant increase in the withdrawal rate for those who took advantage of flat rate tuition, this rate kept going down and after five years came to alevel similar to that beforethe change in tuition policy. Therefore, we can say that the implementation of flat rate tuition hashad an overall positive effect on academic progress at RS College.

Whether the currentfour year graduation rates for this institution persist into the future, and to extent to which FRB students are succeeding relative to their NonFRB counterparts are some of the next major questions that we look forward to answering as new data become available. Further, investigating the relationship between different majors and graduation rates is another topic for future study.

Finally, examining data from other institutions who have implemented flat rate tuition policies will permit researchers to investigate the generalizability of the results that RSC experienced. If available, a broader study that considers differences in institutional control (public/private), size, setting, and composition of majors would also yield significant results for higher education overall.

\section{References}

1. Archibald, R.B. and Feldman, D.H. (2006). State higher education spending and the tax revolt. The Journal of Higher Education, 77(4), 618-644.

2. Bien, P. 2009. Tuition: Towards a fair student contribution for higher education. Ontario Undergraduate Student Alliance Policy Paper. Available: http://www.ousa.ca/wordpress/wp-content/uploads/2010/12/Tuition.pdf

3. Cheslock, J. J. and Hughes, R. P. (2011). Differences across states in higher education finance policy. Journal of Education Finance, 36(4), 369-393.

4. Chhatwal, G., Keenan, C. and Wang, J. (2013). Flat Rate Tuition - Observations and analysis of student persistence and performance. International Journal of Research in Educational Methodology (IJREM), 4(2), 473 483. Council for Innovative Research, ISSN 2278-7690. http://cirworld.com/index.php/IJREM/issue/archive

5. Cur, B.R. and Singell, L.D. (2010). Aim high or go low? Pricing strategies and enrollment effects when the net price elasticity varies with need and ability. The Journal of Higher Education, 81(4), 515-543.

6. DeAngelo, L., Franke, R., Hurtado, S., Pryor, J.H. and Tran, S. (2011). Completing college: Assessing graduation rates at four-year institutions. Los Angeles: Higher Education Research Institute, UCLA.

7. Dougherty, K.J., Nienhusser, H.K., and Vega, B.E.(2010). Undocumented immigrants and state higher education policy: The politics of in-state tuition eligibility in Texas and Arizona. The Review of Higher Education, 34(1), 123173.

8. Flores, S.M. (2010). State dream acts: The effect of in-state resident tuition policies and undocumented Latino students. The Review of Higher Education, 33(2), 239-283.

9. Heller, D.E. (1999). The effects of tuition and state financial aid on public college enrollment. The Review of Higher Education, 23(1), 65-89.

10. Morgan, J. N. (1983). Tuition policy and the interstate migration of college students. Research in Higher Education, 19(2), 183-195.

11. Selingo, J. (2001). Colleges and lawmakers push students to graduate in 4 years. Chronicle of Higher Education, 48(11), A22-A24.

12. Shin, J., and Milton, S. (2006). Rethinking tuition effects on enrollment in public four-year colleges and universities. Review of Higher Education, 29(2), 213-237.

13. Titus, M. (2009). The production of bachelor's degrees and financial aspects of state higher education policy: A dynamic analysis. The Journal of Higher Education, 80(4), 439-468.

14. Titus, M. and Pusser, B. (2011).States' potential enrollment of adult students: A stochastic frontier analysis. Research in Higher Education, 52(6), 555-571.

15. Trout, M. (1983). Deciding tuition structure with linear programming. Research in Higher Education, 18(3), 359371.

16. US Department of Education. (2011). College Affordability and Transparency Center. Available: http://collegecost.ed.gov/catc/

17. Yanikoski, R. and Wilson, R. (1984). Differential pricing of undergraduate education. Journal of Higher Education, 55, 735-750. 